\title{
Trunk Flexion to Extension Strength Ratio of 11- to 18-Year Old Youth Ski Racers: Data from 15 Years of Talent Development in Austria
}

\author{
Lisa Steidl-Müller ${ }^{1} \mathbb{D} \cdot$ Carson Patterson $^{1} \cdot$ Roland Luchner $^{1} \cdot$ Christoph Ebenbichler $^{1} \cdot$ Carolin Hildebrandt $^{1}$. \\ Christian Raschner ${ }^{1}$
}

Received: 25 September 2020 / Accepted: 26 January 2021

(c) The Author(s) 2021

\begin{abstract}
Purpose The aim of the present study was to evaluate the trunk strength capacity of alpine ski racers aged 10-18 years, who were tested during the last 15 years, to identify reference values for trunk flexor to extensor strength ratios according to age and sex.

Methods In total, 2841 participants (1605 males, 1236 females; 10-18 years) were included, who were pupils of a famous skiing-specific secondary modern school or members of the provincial ski team between 2006 and 2020. The maximum isometric trunk flexion and extension strength was measured using the slightly modified Back Check. Sex-specific differences were assessed with Student's $t$ test or Mann-Whitney- $U$ test. Univariate analyses of variance or Kruskal-Wallis- $H$ tests were used to assess differences between age groups. Descriptive sex- and age-specific reference values were calculated (norm area: mean $\pm 1 / 2$ standard deviation).

Results Sex-specific differences were found for both flexion (starting at 11 years) and extension strength (starting at 12 years) $(P<0.001)$. Lower flexion to extension strength ratios were identified for males $(0.89 \pm 0.18)$ compared with females $(0.82 \pm 0.15)$, but the ratios remained constant across age groups for both sexes.

Conclusion The present study provides age- and sex-specific reference values for trunk flexion to extension strength ratios for 10- to 18-year old youth and adolescent ski racers. The data of the present study represent a large data pool of youth ski racers at a high-performance level; thus, coaches can use the reference values for comparing the ratios of their athletes.
\end{abstract}

Keywords Core strength $\cdot$ Youth athletes $\cdot$ Alpine ski racing $\cdot$ Talent development

\section{Introduction}

Alpine ski racing is one of the riskiest and fastest nonmotorized sports [4]. It is a physically demanding sport with repeated bidirectional turns in often unpredictable competitive environments [34]. A high level of physical fitness is crucial to compensate for the high external loads intensified by external influences, such as changing snow and weather conditions, and the diverse requirements in different disciplines [34]. This includes high levels of aerobic and anaerobic capacity, muscular strength and power, flexibility, as well as complex motor abilities, such as balance and agility [9, 14, 34]. There is no single fitness parameter predictive for

Lisa Steidl-Müller

lisa.steidl-mueller@uibk.ac.at

1 Department of Sport Science, University of Innsbruck, Innsbruck, Austria success in alpine ski racing, however, high levels of aerobic power and muscle strength are most crucial $[9,10,14,21$, 22]. This is also true for youth ski racing, in which success relies on the complex interaction of technical and physiological characteristics, and not on a single fitness parameter [7]. A good foundation in these characteristics should already be laid at a young age,which emphasizes the high importance of a high level of physical fitness in the talent development in alpine ski racing [24]. Physical performance tests are also part of the entrance exams for skiboarding schools (skiingspecific secondary modern schools, skiing-specific grammar schools); a fact that additionally emphasizes the importance of high levels of physical fitness in young ski racers in Austria [24].

Different turn radii and speeds in diverse disciplines of alpine ski racing generate strong kinetic forces; thus, the maintenance of balance under challenging strength situations is crucial for elite performance, as well as for injury 
prevention [29]. In particular, trunk muscles are important to minimize alterations in ski racing stance [13], and in compensating for external forces and loads during ski racing [30]. Additionally, trunk strength is seen as a critical factor for preventing knee injuries in adolescent alpine ski racers (15-19 years [26]), injuries in youth ski racers (10-14 years [20]), and overuse injuries in elite ski racers [30]. Concerning overuse injuries, it was reported that excessive competitive sports during youth and insufficient trunk stability provoke low back pain (LBP) [28], which is a growing problem in elite ski racing [29], and adolescent ski racing [12]. Even though LBP does not represent such a severe problem in youth ski racing as knee injuries do [20], it might be assumed that the severity of LBP problems increases with age [12, 31]. Insufficient trunk strength, inappropriate recruitment of the trunk muscles and imbalances of these muscles may contribute to LBP [3]. The importance of a well-developed trunk strength already in young athletes might be emphasized by the trend showing that youth and adolescent ski racers (10-18 years), who were tested during 2015-2019, showed significantly higher trunk strength characteristics compared with athletes tested 10-15 years before,the differences were found in all age groups and in both males and females with large effect sizes [32]. The authors concluded that recent trends in athletic training (cross-training, slackline training), as well as the shift from strength endurance to maximal strength training in the context of core strength training might have affected this development [32].

Previous research showed that male athletes had significantly better trunk strength characteristics than their female counterparts $[2,8,11,16,17]$. Sex-specific differences in trunk strength were found also in non-athletic populations $[1,11]$. The younger the athletes were, the smaller the sexspecific differences were distinctive, as Malina [15] revealed smaller sex-specific differences in absolute peak torque values for pre-pubertal athletes (younger than 12 years) than for pubertal athletes ( $>12$ years). This trend might be explained by the disproportional rise of trunk strength with age among male athletes, whereas in females such an increase was not identified due to normalization to body weight [17].

However, there is a lack of research identifying sportspecific trunk strength characteristics and optimal flexion/ extension ratios, especially in youth and adolescent ski racers. Hildebrandt et al. [11] investigated the isokinetic core strength of elite ski racers and compared them with physically active controls and revealed that the ski racers had significantly higher strength values in both males and females. However, no differences were found in the flexion/ extension ratio between the ski racers and the controls, both groups showed relatively low ratios (0.54-0.59), which indicates high trunk extensor muscles relative to flexor muscles [11]. These values were in line with studies investigating for example long-distance race car drivers [2] and elite rowers [16], in which ratios of 0.5-0.7 were identified, whereas in healthy untrained adults the ratios were higher (0.7-0.9) [2, 16]. Even though the ratio of absolute flexor to extensor strength is often used to evaluate trunk strength capacity $[16,18,19]$, and despite the ongoing discussions about an optimal ratio among practitioners, no reference values for youth and adolescent ski racers exist. However, such reference values would be helpful for coaches for being able to estimate the strength level of their athletes. Therefore, the aim of the present study was to evaluate the trunk strength capacity of a large pool of elite alpine ski racers aged 10-18 years to identify reference values for trunk flexor to extensor strength ratios according to age and sex. It was hypothesized that male athletes would generate higher trunk flexion and extension strength values than their female counterparts. Additionally, it was hypothesized that trunk flexion to extension strength ratios would remain constant across diverse age groups.

\section{Methods}

\section{Study Design and Ethical Approval}

A cross-sectional study design was used to evaluate trunk strength capacity in young athletes of different ages and sexes. The present study represents a retrospective study of data obtained over a period of 15 years. All tests were performed in the laboratory of the Department of Sport Science of the University of Innsbruck by experienced researchers. To ensure repeatability and to limit influences, the tests were conducted at approximately the same time of day and under standardized laboratory conditions. The athletes had to wear standardized shoes of the laboratory and typical training clothes. After a standardized 15-min general warm-up, a specific warm-up for the core was performed. The parents or coaches of the athletes signed a written informed consent for participation in the testing and gave their permission to the scientific processing of the data. The participation in the testing was voluntary. The procedures are in accordance with the ethical standards of the Declaration of Helsinki and were approved by the Institutional Review Board.

\section{Participants}

In the present study, either ski racers of a skiing-specific boarding school or members of the provincial junior ski team were included: 2841 participants (1605 males, 1236 females), who were tested between 2006 and 2020. The number of participants included per age group is presented in Table 1 separated by sex. Due to several reasons (illness, injury, fluctuation, end of career, other reasons), some 
Table 1 Number of athletes included per age group

\begin{tabular}{llll}
\hline Age group & Males & Females & Total \\
\hline 10 & 60 & 38 & 98 \\
11 & 155 & 114 & 269 \\
12 & 206 & 162 & 368 \\
13 & 253 & 195 & 448 \\
14 & 248 & 200 & 448 \\
15 & 205 & 168 & 373 \\
16 & 168 & 129 & 297 \\
17 & 174 & 129 & 303 \\
18 & 136 & 101 & 237 \\
total & 1605 & 1236 & 2841 \\
\hline
\end{tabular}

athletes were tested only once or twice and others were tested up to 9 times in consecutive age groups. The data included were from 820 athletes (463 males, 357 females). One hundred and forty-three athletes were tested only once; 163 athletes were tested twice; 141 were tested three times; 157 were tested four times; 96 were tested five times; 57 were tested six times; 40 were tested seven times; 23 were tested eight times and four athletes were tested nine times; thus, in total 2841 participants were included.

\section{Data Collection}

\section{Anthropometric Characteristics}

Body height $(0.5 \mathrm{~cm})$ was recorded using a portable stadiometer SECA 217 (SECA, Hamburg, Germany). Body mass $(1 \mathrm{~N})$ was measured on a Kistler force plate (Kistler Instrumente AG, Gommiswald, Switzerland) with normal sports clothes but without shoes, and was then calculated to the nearest $0.1 \mathrm{~kg}$. Body mass index (BMI; $0.1 \mathrm{~kg} / \mathrm{m}^{2}$ ) was calculated as body mass in kilograms divided by height in meter squared.

\section{Trunk Flexion and Extension Strength}

The isometric trunk flexion and extension strength test is part of the test battery for junior ski athletes as described by Raschner et al. [25], which was established in consultation with sports scientists, ski racing experts and coaches.

The maximal isometric trunk flexion and extension strength were measured using the slightly modified Back-Check (Dr. Wolff Sports \& Prevention GmbH, Arnsberg, Germany). The athlete stands upright on the standing platform of the Back-Check test device (see Fig. 1), with the foot position being exactly defined according to the length of the foot. To guarantee correct foot position during testing, additional sensors control heel contact with the platform. By means of a template the angles of the ankle joints are set

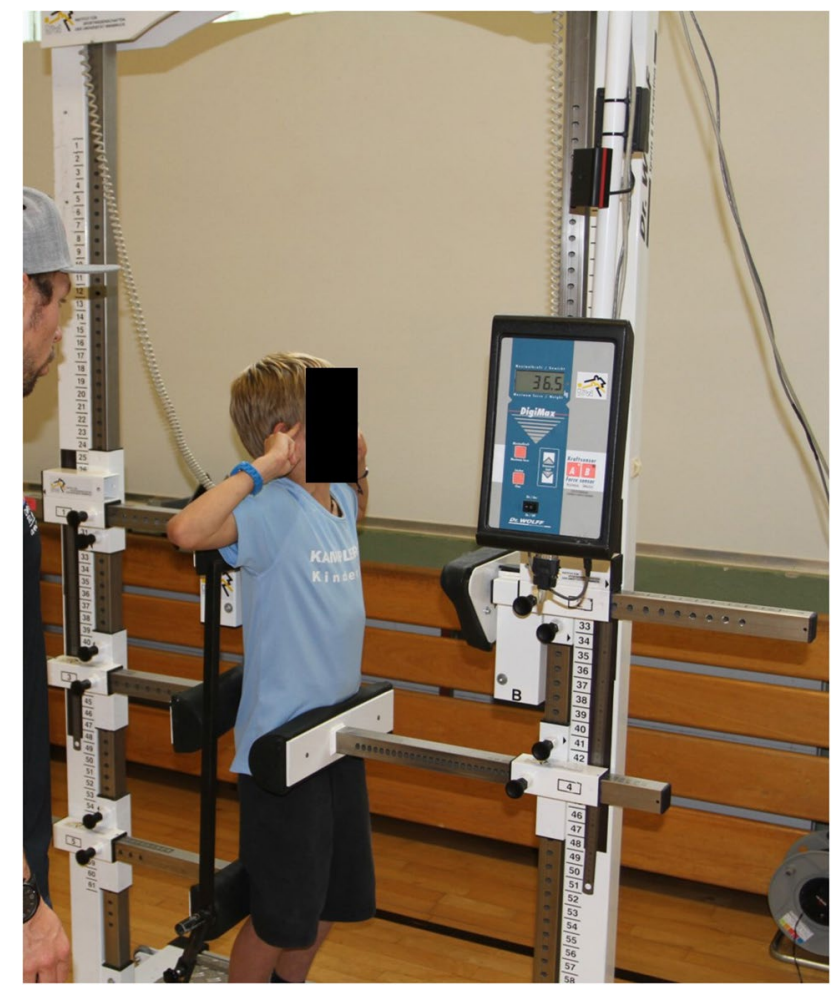

Fig. 1 Back Check device (athlete performs trunk extension test)

to $75^{\circ}$ and the knees are slightly flexed. After adjustment, fixation pads are positioned in the area of the hollow of the knee and the pelvis to prevent movement during the test. Cushioned measurement pads which are connected to force transducers are set at sternum level anteriorly (for flexion strength test) and posteriorly (for extension strength test).

For the flexion test, the athlete contracts maximally three times for three seconds each against the anteriorly positioned measurement pad. After a one-minute break, the extension test is performed using the same procedure. Between the three flexion/extension tests, the software (LabView, National Instruments, Austin, USA) provides a 30-s break. The highest force of the three attempts for flexion and extension is recorded. The ratio of flexion to extension strength was then calculated by dividing the flexion strength by the extension strength. The test-retest reliability analysis among high-level athletes identified ICCs of 0.77 (flexion) and 0.90 (extension) [23]. Another study that assessed the reliability of the Back Check device, identified ICC values of 0.88 for flexion and 0.89 for extension [27].

\section{Data Analyses}

All calculations were computed using IBM SPSS statistics version 25.0 (SPSS Inc., Chicago, IL, USA). Microsoft Excel (Version 2010, Microsoft, Seattle, WA, USA) was used for tables and Origin (Version Pro 9, OriginLab, 
Northampton, MA, USA) was used for figures. The normal distribution was tested using the Kolmogorov-Smirnov-test. Sex-specific differences in anthropometric characteristics as well as trunk strength characteristics were calculated with the Student's $t$ test or the Mann-Whitney- $U$ test for independent samples. Univariate analyses of variance (contrast: Helmert; post-hoc: Scheffé) or Kruskal-Wallis- $H$ tests were used to assess differences in trunk strength parameters between age groups. Effect sizes were calculated: Cohen's $d$ for $t$ test-calculations and Pearson correlation coefficient $r$ for Mann-Whitney- $U$ test-calculations. Cohen's $d$ was interpreted as 0.2 (small), 0.5 (medium), and $>0.8$ (large) effects, respectively [5] and $r$ was interpreted as 0.1 (small), 0.3 (medium), and $>0.5$ (large) effects [6]. The level of significance was set at $P<0.05$.

Descriptive reference values were calculated (separately for males and females) for each age group. The norm area was defined as mean (M) of the ratio (of each age group) $\pm 1 / 2$ standard deviation (SD). Higher values than $M+1 / 2 S D$ was defined as "extension strength too low compared to flexion strength" and lower values than $\mathrm{M}-1 / 2 \mathrm{SD}$ was defined as "flexion strength too low compared to extension strength".

\section{Results}

\section{Anthropometric Characteristics}

The anthropometric characteristics of male and female youth ski racers of the different age groups are presented in Table 2. Additionally, the results of the sex-specific difference analyses are reported, as well. Male and female youth ski racers significantly differed in body height starting at the age group of 14 years; male athletes were taller. Males and females significantly differed in body weight in the age
Table 2 Anthropometric characteristics of athletes, differences by age group and by sex

\begin{tabular}{|c|c|c|c|c|c|}
\hline \multirow[t]{2}{*}{ Age group } & \multirow[t]{2}{*}{ Males } & \multirow[t]{2}{*}{ Females } & \multicolumn{3}{|l|}{ Sex differences } \\
\hline & & & $\mathrm{T} / \mathrm{U}$ statistics & $P$ & Effect size \\
\hline \multicolumn{6}{|c|}{ Body height (cm) } \\
\hline 10 & $142.3 \pm 5.6$ & $141.3 \pm 4.2$ & $t(96)=1.199$ & 0.234 & $d=0.20$ \\
\hline 11 & $146.2 \pm 5.7$ & $146.3 \pm 6.0$ & $t(267)=-0.075$ & 0.940 & $d=0.02$ \\
\hline 12 & $151.4 \pm 6.2$ & $153.4 \pm 6.6$ & $t(366)=-1.483$ & 0.139 & $d=0.31$ \\
\hline 13 & $158.4 \pm 7.5$ & $158.5 \pm 6.1$ & $t(446)=-0.187$ & 0.851 & $d=0.02$ \\
\hline 14 & $166.3 \pm 8.0$ & $162.6 \pm 5.5$ & $t(446)=5.619$ & $<0.001$ & $d=0.54$ \\
\hline 15 & $173.2 \pm 6.7$ & $165.5 \pm 5.4$ & $z=-10.643$ & $<0.001$ & $r=0.55$ \\
\hline 16 & $177.0 \pm 5.7$ & $166.2 \pm 5.6$ & $t(295)=16.181$ & $<0.001$ & $d=1.91$ \\
\hline 17 & $178.6 \pm 5.5$ & $166.6 \pm 5.6$ & $t(301)=18.602$ & $<0.001$ & $d=2.16$ \\
\hline 18 & $179.5 \pm 5.7$ & $166.5 \pm 5.2$ & $t(235)=18.113$ & $<0.001$ & $d=2.38$ \\
\hline \multicolumn{6}{|c|}{ Body weight $(\mathrm{kg})$} \\
\hline 10 & $34.9 \pm 5.4$ & $33.5 \pm 4.2$ & $z=-1.028$ & 0.304 & $r=0.10$ \\
\hline 11 & $37.7 \pm 6.2$ & $37.2 \pm 5.0$ & $z=-0.21$ & 0.984 & $r=0.01$ \\
\hline 12 & $41.6 \pm 6.5$ & $42.7 \pm 6.1$ & $z=-2.012$ & 0.044 & $r=0.10$ \\
\hline 13 & $47.5 \pm 8.0$ & $49.3 \pm 7.1$ & $z=-2.784$ & 0.005 & $r=0.13$ \\
\hline 14 & $55.0 \pm 9.0$ & $54.8 \pm 6.4$ & $z=-0.032$ & 0.975 & $r=0.00$ \\
\hline 15 & $63.6 \pm 8.8$ & $59.2 \pm 6.1$ & $z=-5.692$ & $<0.001$ & $r=0.29$ \\
\hline 16 & $70.0 \pm 7.5$ & $61.0 \pm 6.1$ & $t(295)=11.088$ & $<0.001$ & $d=1.37$ \\
\hline 17 & $73.3 \pm 7.0$ & $62.4 \pm 5.8$ & $t(301)=14.428$ & $<0.001$ & $d=1.70$ \\
\hline 18 & $76.0 \pm 7.3$ & $62.8 \pm 5.7$ & $t(235)=15.183$ & $<0.001$ & $d=2.02$ \\
\hline \multicolumn{6}{|c|}{ BMI $\left(\mathrm{kg} / \mathrm{m}^{2}\right)$} \\
\hline 10 & $17.2 \pm 2.0$ & $16.8 \pm 1.7$ & $z=-0.689$ & 0.491 & $r=0.07$ \\
\hline 11 & $17.6 \pm 2.0$ & $17.4 \pm 1.6$ & $z=-0.301$ & 0.764 & $r=0.02$ \\
\hline 12 & $18.1 \pm 2.0$ & $18.4 \pm 1.8$ & $t(366)=-1.154$ & 0.249 & $d=0.16$ \\
\hline 13 & $18.9 \pm 2.0$ & $19.6 \pm 2.1$ & $t(446)=-3.467$ & 0.001 & $d=0.34$ \\
\hline 14 & $19.8 \pm 1.9$ & $20.8 \pm 2.1$ & $t(446)=0.224$ & 0.823 & $d=0.50$ \\
\hline 15 & $21.2 \pm 2.0$ & $21.6 \pm 1.9$ & $t(371)=-2.329$ & 0.020 & $d=0.21$ \\
\hline 16 & $22.4 \pm 1.9$ & $22.1 \pm 1.9$ & $z=-2.350$ & 0.019 & $r=0.14$ \\
\hline 17 & $23.0 \pm 1.8$ & $22.5 \pm 1.7$ & $t(301)=2.39$ & 0.017 & $d=0.29$ \\
\hline 18 & $23.6 \pm 1.8$ & $22.7 \pm 1.6$ & $t(235)=4.008$ & $<0.001$ & $d=0.53$ \\
\hline
\end{tabular}


group of 13 years, females were heavier. Starting at the age group of 15 years, male athletes were significantly heavier.

\section{Trunk Strength and Trunk Flexion to Extension Strength Ratio}

The relative trunk flexion and relative trunk extension strength values, as well as the flexion to extension strength ratios are reported in Table 3 separated by sex and age group. Male and female athletes significantly differed in relative trunk flexion strength starting at the age group of 11 years; male athletes were significantly stronger. The significant sex-specific differences were apparent in relative trunk extension strength starting at the age group of 12 years onwards; male athletes had higher values, as well. The trunk flexion to extension strength ratio significantly differed between males and females starting at the age group of 11 years. Male athletes showed higher ratios.
The trunk flexion to extension strength ratios are presented in Fig. 2. The analyses of variance showed that the flexion to extension strength ratio of male and female athletes did not significantly differ between age groups $(P>0.05)$ (Fig. 2). The reference values of trunk flexion to extension strength ratios are presented in Fig. 3 for female athletes and in Fig. 4 for male athletes.

\section{Discussion}

Trunk strength plays a crucial role in alpine ski racing in terms of compensating for external loads during racing and in the injury prevention context, especially for preventing knee injuries, as well as low back pain [29]. However, no studies exist that report reference values of trunk strength capacities as well as trunk flexor to extensor strength ratios for youth and adolescent ski racers. Therefore, the aim of
Table 3 Trunk strength characteristics of athletes, differences by age group and by sex

\begin{tabular}{|c|c|c|c|c|c|}
\hline \multirow[t]{2}{*}{ Age group } & \multirow[t]{2}{*}{ Males } & \multirow[t]{2}{*}{ Females } & \multicolumn{3}{|l|}{ Sex differences } \\
\hline & & & $\mathrm{T} / \mathrm{U}$ statistics & $P$ & Effect size \\
\hline \multicolumn{6}{|c|}{ Relative trunk flexion strength $(\mathrm{N} / \mathrm{kg})$} \\
\hline 10 & $8.78 \pm 1.79$ & $8.34 \pm 2.20$ & $t(96)=1.087$ & 0.280 & $d=0.22$ \\
\hline 11 & $10.02 \pm 2.07$ & $9.02 \pm 1.83$ & $t(267)=4.071$ & $<0.001$ & $d=0.51$ \\
\hline 12 & $10.20 \pm 2.20$ & $9.29 \pm 2.18$ & $z=-4.316$ & $<0.001$ & $r=0.22$ \\
\hline 13 & $10.17 \pm 2.03$ & $8.93 \pm 1.96$ & $z=-6.502$ & $<0.001$ & $r=0.31$ \\
\hline 14 & $10.29 \pm 2.15$ & $8.84 \pm 1.66$ & $t(446)=7.804$ & $<0.001$ & $d=0.76$ \\
\hline 15 & $10.80 \pm 1.93$ & $8.90 \pm 1.50$ & $t(371)=10.389$ & $<0.001$ & $d=1.10$ \\
\hline 16 & $11.12 \pm 2.14$ & $8.80 \pm 1.42$ & $t(295)=10.663$ & $<0.001$ & $d=1.28$ \\
\hline 17 & $11.08 \pm 2.37$ & $8.93 \pm 1.53$ & $t(301)=9.012$ & $<0.001$ & $d=1.08$ \\
\hline 18 & $11.32 \pm 2.18$ & $8.86 \pm 1.53$ & $t(235)=9.723$ & $<0.001$ & $d=1.31$ \\
\hline \multicolumn{6}{|c|}{ Relative trunk extension strength $(\mathrm{N} / \mathrm{kg})$} \\
\hline 10 & $10.94 \pm 1.84$ & $10.71 \pm 1.66$ & $t(96)=0.609$ & 0.544 & $d=0.13$ \\
\hline 11 & $11.34 \pm 1.77$ & $10.96 \pm 1.88$ & $z=-1.707$ & 0.088 & $r=0.10$ \\
\hline 12 & $11.31 \pm 1.91$ & $10.92 \pm 1.79$ & $t(366)=3.959$ & $<0.001$ & $d=0.22$ \\
\hline 13 & $11.14 \pm 1.58$ & $10.59 \pm 1.48$ & $t(446)=3.750$ & $<0.001$ & $d=0.36$ \\
\hline 14 & $11.22 \pm 1.70$ & $10.65 \pm 1.50$ & $t(446)=3.689$ & $<0.001$ & $d=0.36$ \\
\hline 15 & $11.69 \pm 1.43$ & $10.90 \pm 1.32$ & $t(371)=5.450$ & $<0.001$ & $d=0.57$ \\
\hline 16 & $12.10 \pm 1.49$ & $10.96 \pm 1.36$ & $t(295)=6.803$ & $<0.001$ & $d=0.80$ \\
\hline 17 & $12.24 \pm 1.51$ & $11.08 \pm 1.39$ & $t(301)=6.799$ & $<0.001$ & $d=0.80$ \\
\hline 18 & $12.35 \pm 1.48$ & $10.89 \pm 1.33$ & $z=-7.391$ & $<0.001$ & $r=0.48$ \\
\hline \multicolumn{6}{|c|}{ Trunk flexion to extension strength ratio (index) } \\
\hline 10 & $0.82 \pm 0.19$ & $0.80 \pm 0.24$ & $z=-0.817$ & 0.414 & $r=0.08$ \\
\hline 11 & $0.87 \pm 0.17$ & $0.83 \pm 0.18$ & $z=-2.352$ & 0.019 & $r=0.14$ \\
\hline 12 & $0.89 \pm 0.19$ & $0.83 \pm 0.18$ & $z=-3.213$ & 0.001 & $r=0.17$ \\
\hline 13 & $0.89 \pm 0.19$ & $0.84 \pm 0.16$ & $z=-2.998$ & 0.003 & $r=0.14$ \\
\hline 14 & $0.90 \pm 0.19$ & $0.82 \pm 0.13$ & $z=-4.584$ & $<0.001$ & $r=0.22$ \\
\hline 15 & $0.90 \pm 0.15$ & $0.82 \pm 0.11$ & $z=-5.456$ & $<0.001$ & $r=0.28$ \\
\hline 16 & $0.90 \pm 0.17$ & $0.80 \pm 0.12$ & $z=-5.362$ & $<0.001$ & $r=0.31$ \\
\hline 17 & $0.89 \pm 0.19$ & $0.81 \pm 0.12$ & $z=-3.685$ & $<0.001$ & $r=0.21$ \\
\hline 18 & $0.90 \pm 0.17$ & $0.81 \pm 0.13$ & $z=-3.950$ & $<0.001$ & $r=0.26$ \\
\hline
\end{tabular}




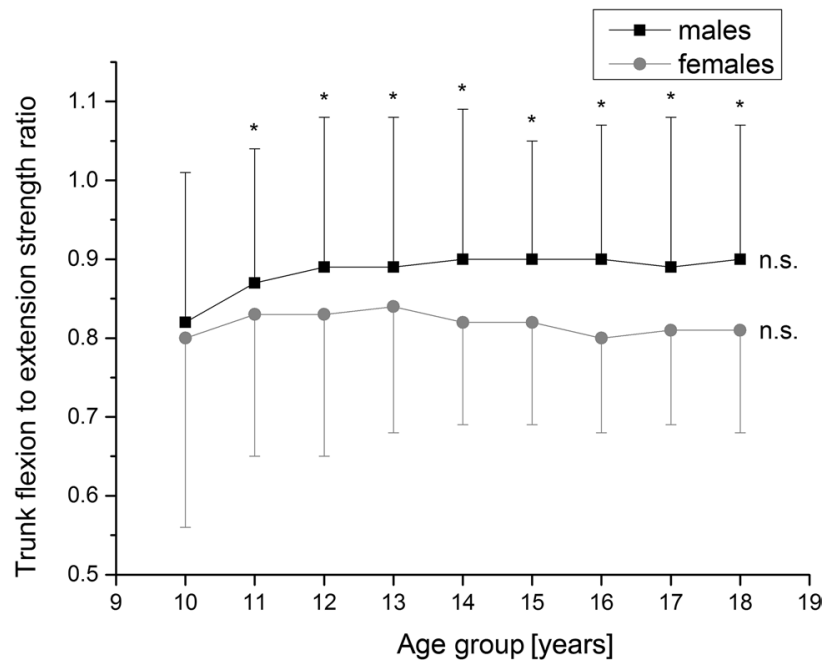

Fig. 2 Age- and sex-specific comparison of trunk flexion to extension strength ratio

the present study was to evaluate the trunk strength characteristics of elite youth and adolescent alpine ski racers aged 10-18 years, who were tested during the last 15 years, and to identify reference values for trunk flexor to extensor strength ratios according to age and sex.

In male athletes, the absolute and relative trunk extension and flexion strength parameters increased with age. The 10-year old male athletes had mean values of $8.78 \pm 1.79 \mathrm{~N} / \mathrm{kg}$ in flexion strength and $10.94 \pm 1.84 \mathrm{~N} /$ $\mathrm{kg}$ in extension strength, whereas 18 -year old male athletes achieved values of $11.32 \pm 2.18 \mathrm{~N} / \mathrm{kg}$ (flexion) and $12.35 \pm 1.48 \mathrm{~N} / \mathrm{kg}$ (extension). In female athletes, the trunk flexion and extension strength values did not increase with age. 10-year old females showed mean values of $8.34 \pm 2.20 \mathrm{~N} / \mathrm{kg}$ (flexion) and $10.71 \pm 1.66 \mathrm{~N} / \mathrm{kg}$ (extension), and 18-year old female athletes achieved only slightly higher values: $8.86 \pm 1.53 \mathrm{~N} / \mathrm{kg}$ (flexion) and $10.89 \pm 1.33 \mathrm{~N} /$ $\mathrm{kg}$ (extension). This increase in male athletes and the stagnation in female athletes are in line with a previous study [17] among young athletes frequenting elite schools of sports in Germany aged 10-15 years. The authors argued that athletic females may achieve their maximum trunk strength capacity at a younger age compared with males. Additionally, they speculated that strength training in females may consider this favorable window of strength development to achieve a suitable basis for further training adaptations [17]. One additional explanation seems to be the normalization of body weight, which might influence the strength development of females more than of males [17]. Male athletes continuously increase their trunk strength capacity with age, probably having not achieved their maximum at the age of 18 years. However, a direct comparison with this study should be interpreted with caution due to the diverse testing modalities, as in the mentioned study isokinetic testing devices were used [17]. Direct comparisons of trunk flexion to extension strength with other studies are not possible, because most studies used isokinetic test devices, and in the present study isometric strength was assessed.

Similar to previous findings in athletic populations [2, $8,11,16,17]$ and non-athletic populations [1, 11], relative trunk strength of male athletes was higher than that of females. The mean female relative trunk flexion strength was approximately $86 \%$ of the mean strength of males. The mean female extension strength was approximately $94 \%$ of the
Fig. 3 Reference values of flexion to extension strength ratio of female athletes

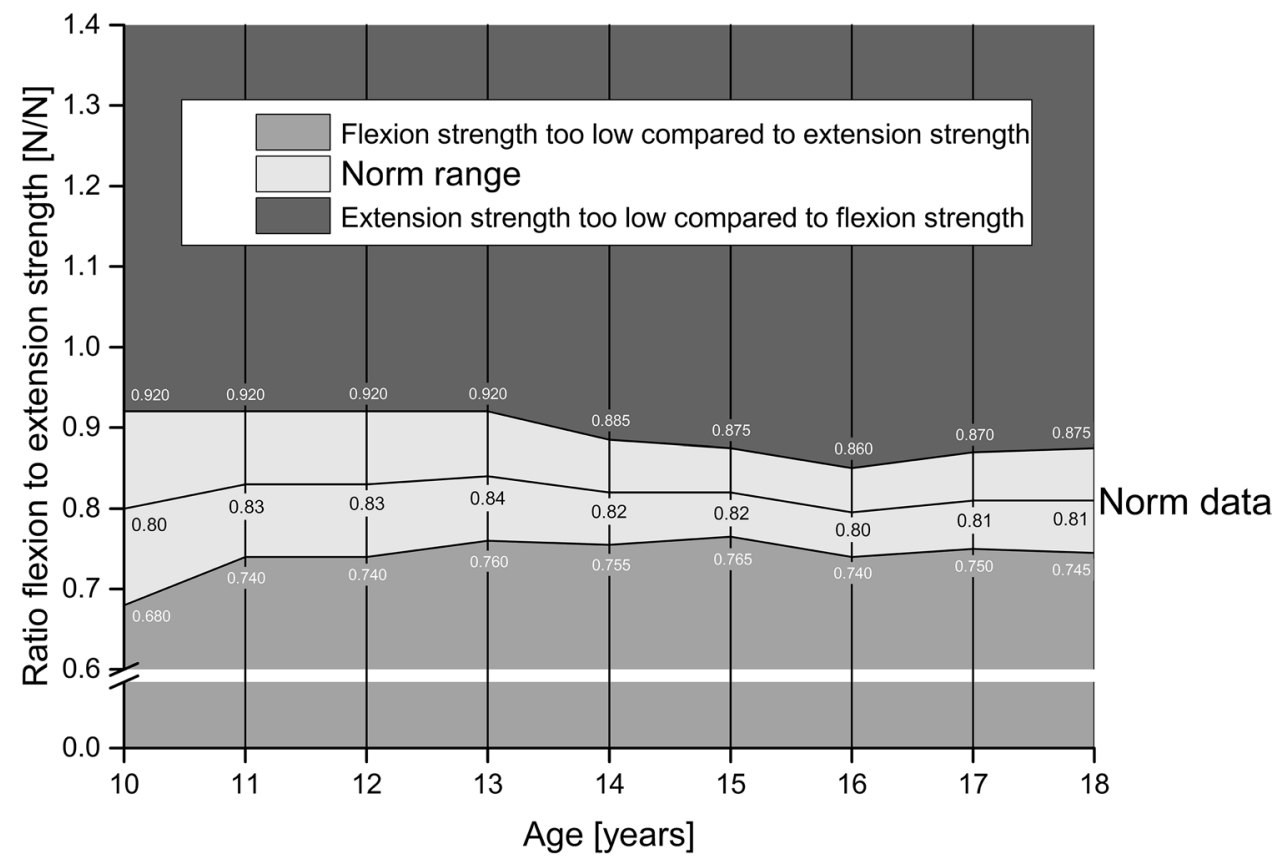


Fig. 4 Reference values of flexion to extension strength ratio of male athletes

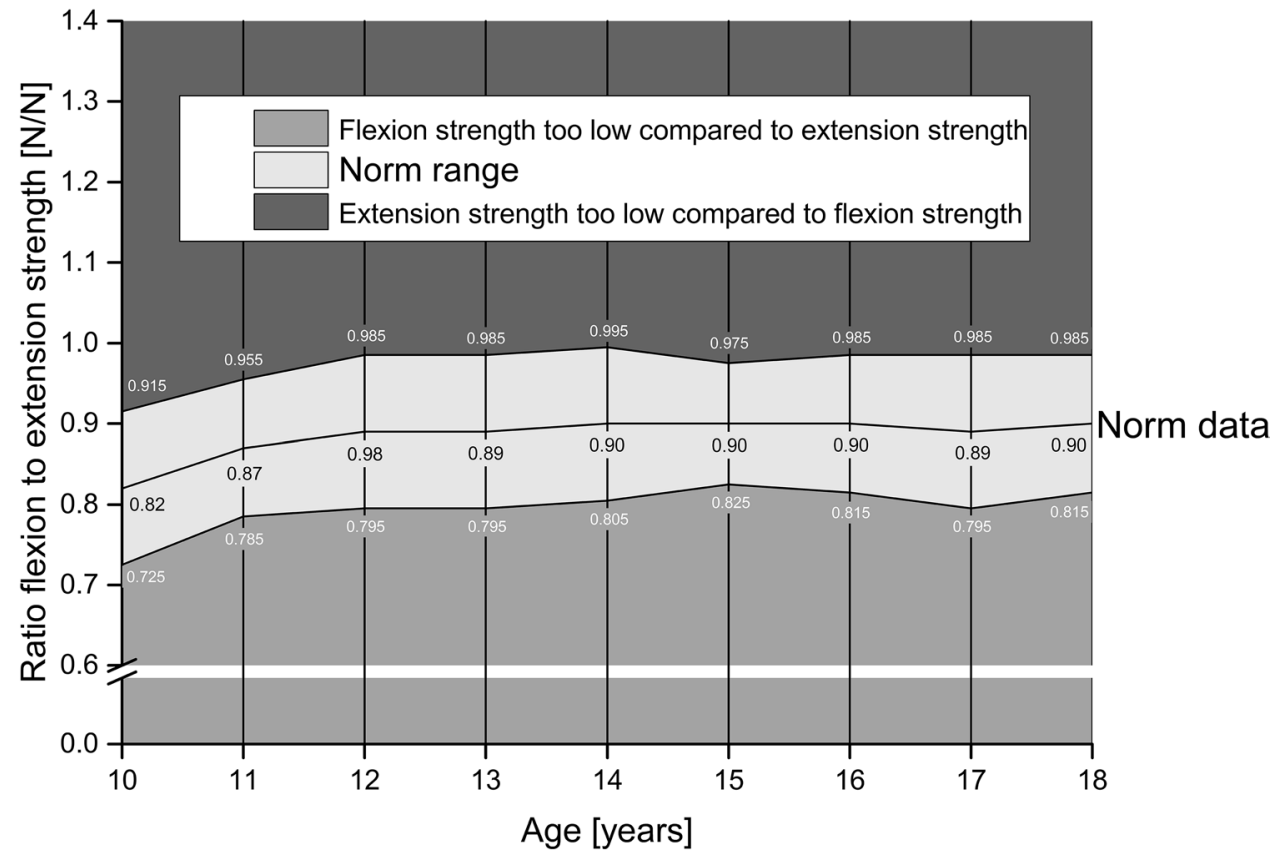

mean strength of the male athletes. These values are much higher than those in elite adult ski racers (70\%-72\% in trunk extension strength) [11]. Significant sex-specific differences were revealed for both relative trunk flexion strength, starting at the age group of 11 years, and relative trunk extension strength, starting at the age group of 12 years. Mean differences in relative trunk flexion strength between males and females were $1.54 \mathrm{~N} / \mathrm{kg}$, and in relative trunk extension strength $0.74 \mathrm{~N} / \mathrm{kg}$. Direct comparisons interpreting the mean differences are difficult due to the fact that previous studies used isokinetic test devices and revealed for example mean differences of $40 \mathrm{~N} \cdot \mathrm{m}$ (flexion) and $60 \mathrm{~N} \cdot \mathrm{m}$ (extension) in trained young athletes [17]. Mueller et al. [17] and Malina [15] found smaller sex differences in absolute peak torque values for prepubertal (11-12 years) and higher differences for pubertal athletes ( $>12$ years). This is in line with the present results, as in relative trunk extension strength no sex-specific differences were found in 10- and 11- year old athletes, and the differences became higher with increasing age, which was also true for relative flexion strength.

The strength ratio of trunk flexion to extension in youth and adolescent ski racers aged 10-18 years remains constant in females $(0.80-0.84)$. In male athletes, the ratio is lower in 10 -year olds $(0.82 \pm 0.19)$ and remains constant starting at the age group of 11 years onwards (0.87-0.90). The analyses of variance did not identify significant differences in the ratio between the diverse age groups for both males and females. This is in line with a previous study in young athletes of elite schools of sports in Germany (10-15 years), in which the ratio remained constant across sexes and age groups [17]. When comparing the strength ratio of the youth ski racers of the present study with young athletes of elite schools of sports aged 10-15 years [17], it becomes obvious that the youth ski racers of both sexes had higher ratios (males: $0.89 \pm 0.18$, females: $0.82 \pm 0.15$ than the athletes of the mentioned study (males: $0.69 \pm 0.15$; females: $0.73 \pm 0.18$ ) [17]. In elite ski racers, relatively low ratios of $0.54-0.59$ were identified [11], which represented a high strength level of trunk extensor muscles relative to flexor muscles. However, both studies [11, 17] used isokinetic testing devices and, therefore, the ratios are not directly comparable, it may be that relatively higher extension forces can be produced during isokinetic measurements relative to flexion strength when comparing with isometric measurements. Nevertheless, interestingly, the youth ski racers showed high flexion strength values relative to extension strength, a fact that leads to the assumption that the importance of trunk strength training in youth athletes is considered very high, maybe due to the studies that identified trunk flexion strength as a critical factor for injuries in youth ski racing [20] and for ACL injuries in adolescent ski racing [26]. During the last decade, the focus in trunk strength training has shifted from strength endurance [14] to maximal strength training, which might have affected especially the trunk flexor muscle [32]. However, this can only be speculated, but it would be in line with findings of a previous study showing a constant increase in trunk strength in youth and adolescent ski racers tested between 2015 and 2019 compared with athletes tested 10-15 years before [32]. In this study, it was hypothesized that recent trends in athletic training, such as cross training or slackline training, have affected core flexion strength. Mueller et al. [19] reported lower trunk flexion to extension 
strength ratios in rowers with higher performance indicating stronger extensor muscles. However, in rowing an asymmetric nature has been speculated to lead to muscle asymmetries, in alpine ski racing a symmetric nature for flexion and extension is required [11]. In the bend forward position during skiing, the extensor muscles generate high forces to counteract the flexion movement [33], however, this might be more relevant in adult athletes as they have experienced more training years including more skiing hours than the younger athletes.

The present study provides age- and sex-specific reference values for trunk flexion to extension strength ratios for 10- to 18-year old youth and adolescent ski racers. The data of the present study represent a large data pool of youth ski racers at a high-performance level; thus, coaches can use the reference values for comparing the ratios of their athletes. However, it has to be considered that no threshold-value can be derived from the present results, for identifying an optimal ratio for injury prevention or performance improvement; nevertheless, the reference values can be used in the talent development of young alpine ski racers in the future. It has to be considered that these reference values are only valid for comparisons using isometric testing devices, such as the Back Check. Whether the values are valid also for other isometric or for isokinetic testing devices has to be proven in future studies.

Funding Open access funding provided by University of Innsbruck and Medical University of Innsbru

vailability of Data and Materials All relevant data are within the manuscript.

\section{Compliance with Ethical Standards}

Conflict of interest The authors declare that there are no conflicts of interest.

Open Access This article is licensed under a Creative Commons Attribution 4.0 International License, which permits use, sharing, adaptation, distribution and reproduction in any medium or format, as long as you give appropriate credit to the original author(s) and the source, provide a link to the Creative Commons licence, and indicate if changes were made. The images or other third party material in this article are included in the article's Creative Commons licence, unless indicated otherwise in a credit line to the material. If material is not included in the article's Creative Commons licence and your intended use is not permitted by statutory regulation or exceeds the permitted use, you will need to obtain permission directly from the copyright holder. To view a copy of this licence, visit http://creativecommons.org/licenses/by/4.0/.

\section{References}

1. Balagué F, Damidot P, Nordin M, Parnianpour M, Waldburger $\mathrm{M}$. Cross-sectional study of the isokinetic muscle trunk strength among school children. Spine. 1993;18(9):1199-205. https:// doi.org/10.1097/00007632-199307000-00013.

2. Baur H, Müller S, Pilz F, Mayer P, Mayer F. Trunk extensor and flexor strength of long-distance race car drivers and physically active controls. J Sport Sci. 2010;28(11):1183-7. https://doi. org/10.1080/02640414.2010.484066.

3. Bergstrøm KA, Brandseth K, Fretheim S, Tvilde K, Ekeland A. Back injuries and pain in adolescents attending a ski high school. Knee Surg Sport Tr A. 2004;12(1):80-5. https://doi.org/ 10.1007/s00167-003-0389-0.

4. Boutin RC, Fritz RC. MRI of snow skiing and snowboarding injuries. Semin Musculoskel R. 2005;9(4):360-78. https://doi. org/10.1055/s-2005-923380.

5. Cohen J. A power primer. Psychol Bull. 1992;112(1):155-9. https://doi.org/10.1037/0033-2909.112.1.155.

6. Cohen J. Statistical power analysis for the behavioral sciences. 2nd ed. Hillsdale: L. Erlbaum Associates; 1988.

7. Emeterio CAS, Gonzáles-Badillo JJ. The physical and anthropometric profiles of adolescent alpine skiers and their relationship with sporting rank. J Strength Cond Res. 2010;24(4):1007-12. https://doi.org/10.1519/JSC.0b013e3181cbabb5.

8. Ezechieli M, Siebert CH, Ettinger M, Kieffer O, Weißkopf M, Miltner O. Muscle strength of the lumbar spine in different sports. Technol Health Care. 2013;21(4):379-86. https://doi. org/10.3233/THC-130739.

9. Gilgien M, Reid R, Raschner C, Supej M, Holmberg HC. The training of olympic alpine ski racers. Front Physiol. 2018;9:1772. https://doi.org/10.3389/fphys.2018.01772.

10. Gorski T, Rosser T, Hoppeler H, Vogt M. An anthropometric and physical profile of young swiss alpine skiers between 2004 and 2011. Int J Sport Physiol. 2014;9(1):108-16. https://doi.org/ 10.1123/ijspp.2013-0223.

11. Hildebrandt C, Müller L, Heisse C, Raschner C. Trunk strength characteristics of elite alpine skiers - a comparison with physically active controls. J Hum Kinet. 2017;57(1):51-9. https://doi. org/10.1515/hukin-2017-0046.

12. Hildebrandt $\mathrm{C}$, Raschner C. Traumatic and overuse injuries among elite adolescent alpine skiers: a two-year retrospective analysis. Int Sportmed J. 2013;14(4):245-55.

13. Hintermeister RA, O'Connor DD, Dillmann CJ, Suplizio CL, Lange GW, Steadman JR. Muscle activity in slalom and giant slalom skiing. Med Sci Sport Exer. 1995;27(3):315-22. https:// doi.org/10.1249/00005768-199503000-00005.

14. Hydren JR, Volek JS, Maresh CM, Comstock BA, Kraemer WJ. Review of strength and conditioning for alpine ski racing. Strength Cond J. 2013;35(1):10-28. https://doi.org/10.1519/ SSC.0b013e31828238be.

15. Malina RM. Weight training in youth - growth, maturation, and safety: an evidence-based review. Clin J Sport Med. 2006;16(6):478-87. https://doi.org/10.1097/01.jsm.00002 48843.31874.be.

16. McGregor A, Hill A, Grewar J. Trunk strength pattern in elite rowers. Isokinet Exerc Sci. 2004;12(4):253-61. https://doi.org/ 10.3233/IES-2004-0183.

17. Mueller J, Mueller S, Stoll J, Baur H, Mayer F. Trunk extensor and flexor strength capacity in healthy young elite athletes aged 11-15 years. J Strength Cond Res. 2014;28(5):1328-34. https:// doi.org/10.1519/JSC.0000000000000280.

18. Mueller S, Mayer P, Baur H, Mayer F. Higher velocities in isokinetic dynamometry: a pilot study of new test mode with active compensation of inertia. Isokinet Exerc Sci. 2011;19(2):63-70. https://doi.org/10.3233/IES-2011-0398.

19. Mueller S, Stoll J, Mueller J, Mayer F. Validity of isokinetic trunk measurements with respect to healthy adults, athletes and low back pain patients. Isokinet Exerc Sci. 2012;20(4):255-66. https:// doi.org/10.3233/IES-2012-00482. 
20. Müller L, Hildebrandt C, Müller E, Fink C, Raschner C. Longterm athletic development in youth alpine ski racing: the effect of physical fitness, ski racing technique, anthropometrics and biological maturity status on injuries. Front Physiol. 2017;8:656. https://doi.org/10.3389/fphys.2017.00656.

21. Neumayr G, Hoertnagl H, Pfister R, Koller A, Eibl G, Raas E. Physical and physiological factors associated with success in professional alpine skiing. Int J Sports Med. 2003;24(8):571-5. https://doi.org/10.1055/s-2003-43270.

22. Patterson C, Raschner C, Platzer HP. The 2.5-minute loaded repeated jump test: evaluating anaerobic capacity in alpine ski racers with loaded countermovement jumps. J Strength Cond Res. 2014;28(9):2611-20. https://doi.org/10.1519/JSC.0000000000 000436.

23. Platzer HP, Raschner C, Patterson C. Performance-determining physiological factors in the luge start. J Sport Sci. 2009;27(3):221-6. https://doi.org/10.1080/02640410802400799.

24. Raschner C, Müller L, Hildebrandt C. Talent detection and development in Alpine skiing. In: Müller E, Kröll J, Lindinger S, Pfusterschmied J, Stöggl T, editors. Science and skiing VI. Maidenhead: Meyer \& Meyer Sport; 2015. p. 65-75.

25. Raschner C, Müller L, Patterson C, Platzer HP, Ebenbichler C, Luchner R, Lembert S, Hildebrandt C. Current performance testing trends in junior and elite Austrian alpine ski, snowboard and ski cross racers. Sport Orthop Sport Traumatol. 2013;29(3):193202. https://doi.org/10.1016/j.orthtr.2013.07.016.

26. Raschner C, Platzer HP, Patterson C, Werner I, Huber R, Hildebrandt $\mathrm{C}$. The relationship between ACL injuries and physical fitness in young competitive ski racers: a 10-year longitudinal study. Brit J Sport Med. 2012;46(15):1065-71. https://doi.org/ 10.1136/bjsports-2012-091050.
27. Scheuer R, Friedrich M. Reliability of isometric strength measurements in trunk and neck region: patients with chronic neck pain compared with pain-free persons. Arch Phys Med Rehab. 2010;91(12):1878-83. https://doi.org/10.1016/j.apmr.2010.09. 009.

28. Schmidt CP, Zwingenberger S, Walther A, Reuter U, Kasten P, Seifert J, Günther KP, Stiehler M. Prevalence of low back pain in adolescent athletes - an epidemiological investigation. Int J Sports Med. 2014;35(8):684-9. https://doi.org/10.1055/s-0033-1358731.

29. Spörri J, Kröll J, Gilgien M, Müller E. How to prevent injuries in alpine ski racing: what do we know and where do we go from here? Sports Med. 2017;47(4):599-614. https://doi.org/10.1007/ s40279-016-0601-2.

30. Spörri J, Kröll J, Haid C, Fasel B, Müller E. Potential mechanisms leading to overuse injuries of the back in alpine ski racing: A Descriptive Biomechanical Study. Am J Sport Med. 2015;43(8):2042-8. https://doi.org/10.1177/0363546515588178.

31. Steidl-Müller L, Hildebrandt C, Raschner C, Müller E. Challenges of talent development in alpine ski racing: a narrative review. J Sport Sci. 2019;37(6):601-12. https://doi.org/10.1080/02640414. 2018.1513355.

32. Steidl-Müller L, Hildebrandt C, Ebenbichler C, Luchner R, Patterson C, Müller E, Gonaus C, Raschner C. Changes in anthropometric and fitness characteristics over a decade of young elite alpine ski racers. Int J Sport Physiol. 2020;16(1):124-34. https:// doi.org/10.1123/ijspp.2019-0889.

33. Tesch PA. Aspects on muscle properties and use in competitive alpine skiing. Med Sci Sport Exer. 1995;27(3):310-4. https://doi. org/10.1249/00005768-199503000-00004.

34. Turnbull JR, Kilding AE, Keogh JWL. Physiology of alpine skiing. Scand J Med Sci Spor. 2009;19(2):146-55. https://doi.org/ 10.1111/j.1600-0838.2009.00901.x. 